\title{
Architectural education and sustainable human habitat in Nigeria
}

\author{
Y. M. D. Adedeji, A. A. Taiwo, O. A. Olotuah \& G. Fadairo \\ Department of Architecture, Federal University of Technology, Nigeria
}

\begin{abstract}
The goal of architectural education is directed towards the attainment of a humane and responsive environment. This is subsumed in the overall purpose of education, which is to prepare people to perpetuate and improve their society. In this endeavour architects are trained to understand the nature of societal problems in their environmental context. This paper takes a critical look at the programmes of architectural education in Nigeria in their bid to contribute to, and improve the quality of the human habitat and ensure its sustainability. It notes the degradation of the environment and housing conditions in Nigeria's urban centres, which is symptomatic of the rapid urbanisation occurring in the country. It asserts that though the curricula in Nigerian architectural schools have been designed to ensure the provision of education that ensures the attainment of professional skills requisite for effective shaping, re-ordering, and articulation of the built environment, there are shortcomings. It proffers recommendations for invigorating architectural education for attaining a sustainable and qualitative human habitat.

Keywords: architecture, curriculum, education, environmental degradation, human habitat, housing, sustainable, urbanisation, Nigeria.
\end{abstract}

\section{Introduction}

Because the main thrust of architectural education is the achievement of sustainable human habitat, its quality is central to architecture. Thus, the goal of architectural education is to contribute to the attainment of a humane and responsive environment. In this endeavour schools of architecture strive to equip students with the education required to make them contribute to the promotion of an orderly development of the human environment. Olotuah and Adesiji [1] state 
that the programmes of schools of architecture in Nigeria lead to the production of professionals who are sensitive to human needs and aspirations and who have the requisite knowledge and the intellectual and aesthetic skills to evolve expressive design solutions of problems of the built environment.

The goal of architectural education is embedded in the general concept of education, which is to prepare people to advance and sustain their society. This is achieved by taking due cognizance of the society's political, social and economic circumstances in the design of the educational programme. In Nigeria rapid urbanisation has outpaced the ability of governments to provide adequate shelter and basic amenities for the urban poor. The high level of poverty of most urban households places the available housing stock out of their economic reach. Many of the households resort to constructing make-shift dwellings with all sorts of refuse materials in illegally occupied land. The result is the development of slums and squatter settlements. Slums are characterized by obsolesce resulting from the combined effects of such factors as natural ageing of buildings, lack of maintenance and neglect, wrong use of buildings, wrong development of land, poor sanitation in the disposal of sewage and solid wastes, and increasing deterioration of the natural landscape $[2,3]$.

In this regard, there is an overarching need for architectural education to address the deplorable situation of the human habitat in Nigeria. This paper takes an incisive look at architectural education in Nigeria and the role it plays in enhancing the achievement of a humane and responsive environment. This is geared towards achieving wellbeing, growth and health of inhabitant of the human habitat.

\section{Architectural education in Nigeria: the curriculum and impact on housing}

The Nigerian College of Arts, Science and Technology was the first school of architecture in Nigeria. It was established in 1952 and it graduated its first set of students in 1961. In 1962 the College was upgraded into a University (Ahmadu Bello University, Zaria) and the programme was restructured for the award of Bachelor of Architecture [3]). The number of institutions awarding degrees in architecture in Nigeria had since risen to eighteen (ten federal, six state, and two private universities). There are also nineteen Polytechnics and Colleges of Technology awarding National Diploma (ND) and/or the Higher National Diploma (HND) in architecture.

Accordingly, Adedeji and Folorunso [4]) observed that the architecture curriculum in Nigerian schools of architecture is largely fashioned after the British and American models of architectural education. This is because programmes were either established by the British or by Nigerians, who themselves underwent the programmes firsthand abroad or Nigeria, leading to what is now regarded as part of the Nigerian colonial experience $[5,6]$. The original programmes have however undergone tremendous changes to reflect national needs and aspirations. The aim has been to ensure that the programmes are relevant to the nation's aspirations and meet current technological 
development. In response to the societal relevance of a course programme curriculum evaluation is carried out from time to time. It is done to ascertain the degree to which the objectives of the programme have been achieved. It furthers enables the determination of the appropriateness of the curriculum for the educational development of a nation. This is particularly important, as the curriculum has to be brought into relation with local conditions with emphasis on the special character of the natural and social environment. An evaluation of the curriculum of architectural education in Nigeria is necessary to ensure that it is still relevant to its set objectives of meeting the nation's needs in this regard.

Schools of architecture in Nigerian universities are guided in their curriculum design by the minimum standards stipulated by the National Universities Commission. Courses are categorised into seven course modules, namely:

i. Architectural Design;

ii. Arts and Drawing;

iii. Historical and Theoretical Studies;

iv. Building Systems Technology;

v. Humanities and Social Studies;

vi. Environmental Control System and

vii. Physical Sciences.

The schools of architecture have over a hundred course titles to choose from in formulating their programme. Their philosophy, and the mission and vision of the University inform the emphasis on the course outline in general. Thus emphasis on housing courses varies from one school to another. In many schools of architecture in Nigeria, courses on housing studies are not even included in the programmes. In a few, housing studies are taught as a part of human settlement studies, and are treated peripherally. At the Federal University of Technology, Akure, for instance out of a total of 256 credit units taken for the Bachelor and Master degrees (B.Tech, M.Tech) only two credit units are taken on Housing in a course entitled Housing Seminar. It is a theory course (Humanities and Social Studies Module) taught in the second semester of the final year of the Bachelor degree $\left(10^{\text {th }}\right.$ semester $)$. The course examines the phenomenon of squatter settlements in developing nations, urban population growth and the demand for shelter. It also examines the incidence of rapid urbanisation and the poverty of the rural communities in developing nations. As a part of the course, discussions are held to explain the solutions to housing problems in developing nations through the adoption of modern and alternative technology systems in housing construction.

Housing studies are inculcated into the curriculum in architectural design, and humanities and social studies modules. Housing is a major component of architectural design studio in most schools of architecture, beginning with elementary study of basic units of the house and culminating in extensive mass housing projects. At the Federal University of Technology, Akure, design of residential buildings is done as part of the design studio in the 2nd year $(200 \mathrm{~L})$, 3rd year (300L) and 5th year (500L). In 200L the course is ARC 201BArchitectural Design II, which is taken in the second semester of the second year ( $4^{\text {th }}$ semester). The course includes 'small scale projects such as simple 
residential designs, restaurants and children playgrounds. Submission requirements include three-dimensional projections, space analysis and functional diagrams.

In the pursuit of development of education system in Nigeria, over the year there has been persistent call for and reviews of colonial-modelled type of architectural educational to pave way for the new challenges evolving from the socio-cultural context of the society. These calls were made at different forum such as the conference of the African Union of Architects (AUA) in 1984, the joint conference of the Nigerian Institute of Architects (NIA) and the Commonwealth of Association of Architects (CAA) in 1988, and Annual General Meeting (AGM) / cum conference of the Association of Architectural Educators in Nigeria (AARCHES) in 2000, 2002 and 2005 respectively. Olotuah [7] stated that education is a culture dependent activity. It is closely related to society and culture, which is only meaningful and purposeful if adequate considerations are given to socio-cultural factors. Education is intertwined with cultural values and the cores of the society. Thus, in the modern day society, where the world is viewed as a global village with networking through the development of information technology placed at the fore, it is imperative to measure the development of architectural education in Nigeria revolving around this standard [8].

\subsection{Sustainable development and housing provision}

Housing is a reflection of the cultural, social and economic values of a society. It is in particular a cultural phenomenon, which finds expression in a people's ability to meet their needs of shelter in the context of their communities. The role of culture in housing is predominant despite the moderating effect of economics, climate, and technology known to them. Housing, a subset of traditional architecture, evolves from the culture of a community in accordance with the lifestyle of its people, the materials of construction available, and technical possibilities open to them $[9,10]$.

The United Nations Conference on Environment and Development - the Earth Summit held in Rio de Janeiro in 1992, created an international framework for the sustainable development of human settlements. In the conference, environmental issues and the natural environment became important guidelines for the realisation of adequate shelter in the century. Prior to Rio de Janeiro international awareness, the techniques of handling the relationship between ecology and the built environment had already become topical among governments and professionals. Architects, planners, environmentalists and engineers were sensitised on issues such as energy consumption, use of environmental friendly materials and design concepts that reduces environmental impact and ensures sustainability.

Sustainable housing provision is the gradual, continual and replicable process of meeting the housing needs of the populace, the vast majority of who are poor and are incapable of providing adequately for themselves. It ensures housing strategies that are stable and are not subject to vagaries in the political circumstances of the country. Sustainable housing provision requires proper 
definition of housing needs, and the participation of the end users to ensure their satisfaction. The general goal of sustainable development is to meet the essential needs of the world's poor while ensuring that future generations have an adequate resources base to meet theirs. It is thus geared towards meeting the needs of the present generation without compromising the ability of future ones to meet their own needs. Achieving sustainability in housing provision requires major societal changes, restructuring of institutions and management approaches. It requires the appropriate political will based on the conviction of the responsibility of government to its citizens, and the need to create humane and decent environment for dignified living. In order to realise sustainable housing provision the housing needs of the Nigerian population have to be put into proper focus, and a coordinated programme to achieve this should be thoroughly worked out. With due consideration given to the input of the local communities, government may initiate aided self-help programmes and low-cost core housing units. It can also facilitate the acquisition of building materials, the cost of which constitutes about $60 \%$ of the entire cost of a building. Production of building materials of indigenous origin by private investors should be given logistic and material support by government (see Figure 1).

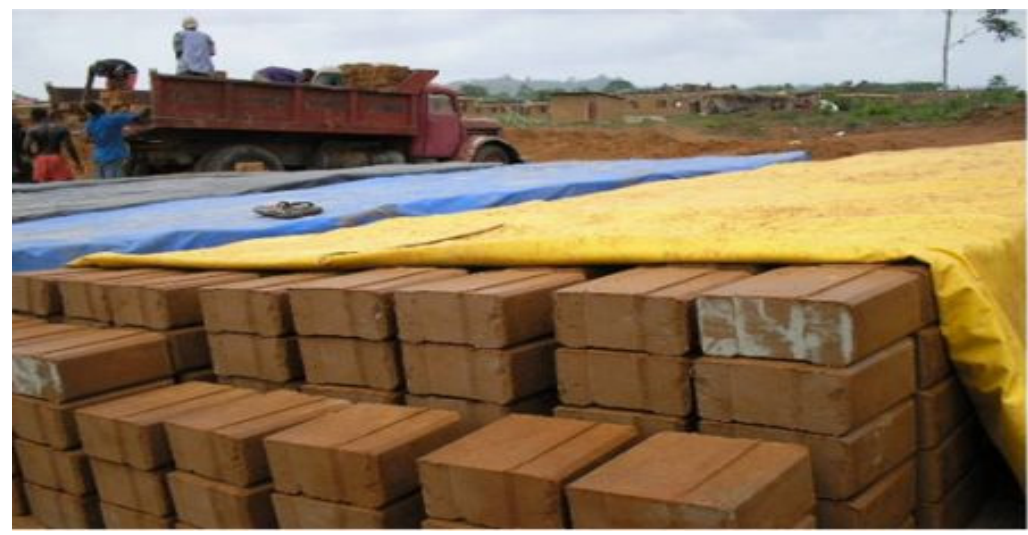

Figure 1: Interlocking blocks produced from laterite and used in Obasanjo low-cost housing estate, Ado-Ekiti, Nigeria.

The building materials include building earth derivatives such as stabilized blocks, clay bricks clay roofing tiles and wood composite materials.

\subsection{Urbanisation and housing in Nigeria}

The most visible and obvious consequences of urbanisation in developing countries, such as Nigeria, is often rapid deterioration of urban housing and living conditions [11]. This is traceable to the fact that urbanisation leads to explosive population growth (see Figure 2), which is occasioned by a phenomenal leap in the quantitative housing needs of the populace [12]. The housing needs are not matched by effective demand since the large majority of 
the populace does not have the wherewithal for adequate housing. According Adejumo [14], the rate of provision of new housing stock has lagged severely behind the rate of population growth in Nigeria resulting in staggering housing deficit requiring an annual production of more than 70,000 housing units to cope with the population trend [14-16].

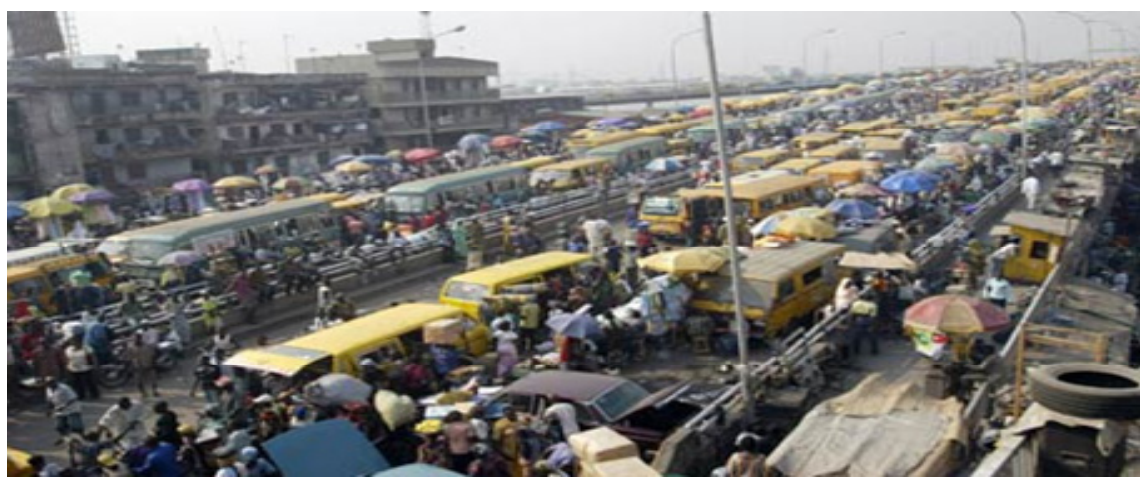

Figure 2: $\quad$ Urban Sprawl as a result of rural-urban drift in Lagos, Nigeria.

Arayela and Taiwo [17] observed that housing shortages have been recorded in both rural and urban communities of all African countries with the latter being more critical. Housing shortages are a worldwide phenomenon though, in most developing and some developed countries. It was against this background that the delegates at the 1976 United Nations Conference on Human Settlements (Habitat) in Vancouver, Canada, demanded a completely new and radical approach to housing policy. The policy was expected to have a strong political and financial commitment by governments especially in helping the poorest citizens of the world.

The rapid increase in the population of urban centres has resulted in an increase in the cost of living because of higher demand on urban commodities. There is a dearth and high cost of urban land, and high cost of housing, which is often in short supply and out of the economic reach of the majority of the urban households [18]. The urban centres are populated by a large mass of people on low wage and who face irregular employment. This segment of the urban population is indeed poor, and is constrained to limited, insufficient, crowded, cold and dirty shelter and a generally degraded environment. These are the urban poor who are subjected to a life characterized by precarious conditions of nutrition and health, little or poor material possessions [19].

As stated by Olotuah [19], most urban centres in Nigeria are characterized by high densities of buildings, the crowding of large numbers of people into those buildings, lack of space for open air living between houses, poor health, substandard housing, and acute environmental and sanitary problems. The shortage of affordable and decent accommodation for the urban poor is thus a major housing problem in Nigeria. In large urban centres poor housing 
conditions often manifest in the high numbers of people living in one room and paying exorbitant rents. This is physical overcrowding, which is a determinant of two major types of problems namely, a health hazard and harmful social behaviour. Overcrowding is a hazard to health where sleeping accommodation is congested and ventilation is poor. Infectious (air and water borne) diseases spread very fast under such conditions [20]. However there are other variables more important than overcrowding in the spread of diseases and thus, it cannot solely be taken as a determining factor. As a determining factor for deleterious social behaviour a causal pattern of linkage between overcrowding and the incidence of pathological behaviour have been variously suggested. Overcrowding is considered to lead to irritation, fatigue and unproductiveness. It is experienced as a syndrome of stress and may lead to the development of either extrovert or repressed sexual behaviour among boys and girls. It is even observed to have a tendency to retard the development of children's communication abilities.

\subsection{Environmental degeneration and housing conditions in Nigeria}

In the developing world, like in Nigeria, rapid urbanisation has outpaced the ability of governments to provide adequate shelter and basic amenities for the urban poor resulting in grievous urban poverty [21]. The high level of poverty of most urban households places the available housing stock out of their economic reach. Many of the households resort to constructing make shift dwellings with all sorts of refuse materials in illegally occupied land. The result is the development of slums and squatter settlements. Slums are characterized by obsolesce resulting from the combined effects of such factors as natural ageing of buildings, lack of maintenance and neglect, wrong use of buildings, wrong development of land, poor sanitation in the disposal of sewage and solid wastes, and increasing deterioration of the natural landscape [22].

The most visible consequence of the rapid urbanisation occurring in Nigerian cities is evidently housing poverty. The monumental magnitude of housing needs, the poor quality of the existing houses and the environment in which they are situated are clear manifestations of this phenomenon. Research has shown that an estimated 2.3 million urban dwelling units are substandard, only $33 \%$ of urban houses can be considered to be physically sound, and $44 \%$ and $19 \%$ require minor and major repairs respectively to bring them to normative and structural quality. Sanitary facilities in most urban dwellings and public services (especially water and electricity supply) are grossly inadequate [23].

\subsection{Housing construction and sustainability}

According to Amado et al. [22], modern housing can be categorised into three types: the fully automated technological house, the ecological house made from a range of features including pre-assembled components, and a lifestyle house that changes to suit the owner's present well being. Improvement of housing efficiency is an imperative preoccupation on the process of house building. The process of housing development should be based on sustainability principles, 
which could be applied in the conception, construction and use of the buildings. The goals of the process are to decrease the environmental costs incurred by inadequate constructive systems and solutions, minimizing the impacts on natural resources, and improving users' comfort [22].

Sustainable housing is "a form of affordable housing that incorporates environmentally friendly and community-based practices. It attempts to reduce the negative impact that homes can have on the environment through choosing better building materials and environmental design" [23].

The curriculum in architecture, though studio-based, should inculcate considerable research input into its postgraduate programme in order to prepare graduate students for a productive academic career. Concern for the environment is imperative in sustainable housing. This is particularly important in the face of changes in climatic conditions occasioned by human activities, which are likely to have significant impact on man. The phenomenon of climate change and global warming has arisen from the continued emission of carbon dioxide and other Green House Gases into the atmosphere. The reduction of carbon dioxide emissions in house construction and domestic housing is thus a critical issue in environmental management. Gilkinson and Sexton [29] pointed out further that consideration should be given to the durability, permeability and buildability of defined material resources, the structures fixity, structural stability and acoustic attributes. Broad social elements of sustainable house construction will be met through innovative design solutions leading to social and environmental improvements.

\section{Policy implications and recommendations}

The Nigerian architect is faced with multi-faceted urban problems. Alongside these are also problems encountered in the rural areas, particularly poor quality of housing. Architectural education in the country has to rise to the challenge of equipping would-be architects with the knowledge and skills for solving the problems. It has to foster their creativity and strengthen their interest, motivation and commitment to improve the environment. Within the general framework provided by the Nigerian National University Commission major shifts have to be made towards emphasizing courses in Humanities and Social Studies, and Historical and Theoretical Studies.

The paucity of facilities and architect-educators to implement the curriculum in architecture schools in the country has been identified as the greatest difficulty faced by architectural education in Nigeria [24]. In order for architectural programmes to meet their set objectives, skilful and qualified architects have to be employed to teach. They will also be engaged in research through which they will make original contributions to the development of an improved theoretical basis for architecture. The curriculum in architecture, though studio-based, should inculcate considerable research input into its postgraduate programme in order to prepare graduate students for a productive academic career. 
Urbanisation has risen unabated in Nigeria over the years resulting in deplorable housing and environmental conditions. There is an overarching need to arrest the rapid rate of urbanisation in the country. Government policies have to be revisited to slow down the urbanisation process. Integrated rural development is imperative in this regard. This should involve the location of educational and health institutions in the rural areas, provision of infrastructural facilities, as well as the development of rural housing which will serve to improve the general living conditions of the rural dwellers.

\section{Conclusion}

This paper has reviewed the architectural education, human habitat and causes of degeneration of human environment in Nigeria. The paper asserted that sustainable human habitat can be achieved through architectural education. It further stressed that that although there are efforts towards that direction in Nigeria, these can still be improved upon. This is achievable by increasing the research contents of architectural curriculum and by placing greater emphasis on social sciences and humanities.

\section{References}

[1] Olotuah, A. O. \& Adesiji, O. S., Housing poverty, slum formation, and deviant behaviour. Papers and Presentations, The Housing Studies Association Conference, University of Lincoln, Lincoln, UK, 8-9 September, 2005. www.lincoln.ac.uk/home/conferences/details/has /PAPER-OLOTUAH.doc

[2] Omole, F. K., Urban Renewal Process Issues and Strategies, Lagos: Nigeria, Concept Books and Publication Company Nig. Ltd, 2000.

[3] Olotuah, A. O. \& Adesiji, O. S., An appraisal of architectural education in Nigeria. Papers and Programme of Built Environment Education Conference, CEBE, London: UK, 5-6 September, 2005 URL: www.cebe.heacademy.ac.uk/news/past_events/bee/files/C2.doc

[4] Adedeji, Y.M.D. \& Folorunso, .C.O., Roles of architectural education in sustainable energy resource buildings in Nigeria. Journal of Association of Architectural Educators of Nigeria (8) 2, pp. 16-21, 2009.

[5] Adeyemi, E. A., A tribute to Prof. E. A Adeyemi, Lest we forget. Text of the keynote address to the $7^{\text {th }}$ Annual General Meeting/ National Workshop of the AARCHES, 24-27 February, 2000, FUT, Akure.

[6] Uji, A. Z., Beyond the critiques of the curriculum of architectural education in Nigeria. Architects and Architecture in Nigeria. A tribute to Prof. E. A Adeyemi, FUT, Akure, 2001.

[7] Olotuah, A.O., Architecture and cultural sensibilities: the implications for national unity. Arts and Social Sciences Forum Journal, pp. 45-56, 2002.

[8] Adedeji, Y.M.D and Aluko, O.O., The effects of new information and communication technology on architectural education in Nigeria. Journal of Association of Architectural Educators of Nigeria (8) 3, pp. 37-42, 2009. 
[9] Gardi, R., Indigenous African architecture. New York: Van Nosnand Reinhold Company, 1973.

[10] Adedeji, Y.M.D. Materials preference options for sustainable low-income housing in selected cities in Nigeria. An unpublished Ph.D Thesis, Department of Architecture, Federal University of Technology, Akure, 2007.

[11] Lewin, A.C., Housing Cooperatives in Developing Countries, New York: John Wiley and Sons, 1981.

[12] Diogu, J.O., Housing the Poor in Nigeria: The Integrated Project Approach, Association of Architectural Educators in Nigeria (AARCHES) Journal, 2(1) pp.1-6, 2002.

[13] Adejumo, A. A., Some Thoughts on Affordable and Social Housing in Nigeria, www.nigeriavillagesquare.com/articles/akintokunbo-a-adejumo/ some-thoughts-on-affordable-and-social-housing-in-nigeria.html, cited online 10 December 2008

[14] Onyebueke, V.U., Prospects of Applying Current Global Data Resources and Experiences in Urban Housing Development in Nigeria, Journal of the Tropical Environment, 2(2) pp.133-148, 2002.

[15] Isimi, B., The Role of The Private Sector in Housing Delivery in Nigeria, Journal of the Nigerian Institute of Architects, 4(4) pp.6-8, 2005.

[16] Okedele, O.S., Adebayo, A, K, Iweka, A. C. O. and Uduma-Olugu, N., Infrastructural Development in Urban Cities: An Evaluation of Housing Delivery and Housing Adequacy in Lagos, Compilation of Seminar Papers, Architecture and the Nigerian Development Agenda II, Architects Colloquium, 24 - 26 March, Shehu Musa Yar'Adua Centre, Abuja, pp.1$16,2009$.

[17] Arayela, O. and Taiwo, A.A., Stabilised laterite bricks as an appropriate walling material technology for increasing housing stock in some selected African countries. Proceedings of XXXVII IAHS, World Housing Congress, October 26-28, Santacher (Cantabria, Spain) on CD, 2010.

[18] Oladapo, R. A. \& Olotuah. A. O., Appropriate Real Estate Laws and Policies for Sustainable Development in Nigeria" Structural Survey (Special Issue), 25 (3/4) pp. 330 - 338, 2007, Emerald Publication, UK, www.emeraldinsight.com/10.1108/02630800710772890

[19] Olotuah, A.O., Housing Development and Environmental Degeneration in Nigeria. The Built \& Human Environment Review, 3, pp. 45-51, 2010.

[20] Adedeji, Y.M.D. \& Owoeye, J.O., Environmental sanitation and health of slum dwellers in Akure. Knowledge Review: Inter-disciplinary Journal of Sciences, 17(2) pp.36-44, 2008.

[21] Olotuah, A. O. \& Ajenifujah A. O., Architectural Education and Housing Provision in Nigeria. CEBE Transactions, Vol. 6, Issue 1, pp. 86-102, April 2009 (17) ISSN: 1745-0322 (Online) 86

[22] Amado, M. P., Pinto, A. J., Santos, C. V., The Sustainable Building Process, Proc. of $X X X V$ IAHS World Congress on Housing Science, Melbourne, Australia, 4-7 September, 2007, CD ROM 
[23] Gilkinson, N, \& Sexton, M., Delivering sustainable homes; meeting requirements: a research agenda; Proc. of XXXV IAHS World Congress on Housing Science, Melbourne, Australia, 4-7 September, 2007, CD ROM

[24] Adeyemi, E.A., The appropriate direction of architectural education in Africa region. Journal of Association of Architectural Educators of Nigeria, 1(3), pp. 38-41, 1996. 